\title{
Diagnosis of Malaria among Blood Donors in Port Harcourt, Nigeria: Microscopy or Rapid Diagnostic Tests?
}

\author{
Kennedy T. Wariso*, Ibinabo L. Oboro \\ Department of Medical Microbiology and Parasitology, University of Port Harcourt Teaching Hospital, Port \\ Harcourt, Nigeria \\ Email: ${ }^{*}$ Kennedy.wariso@yahoo.com
}

Received 22 April 2015; accepted 14 May 2015; published 18 May 2015

Copyright (C) 2015 by authors and Scientific Research Publishing Inc.

This work is licensed under the Creative Commons Attribution International License (CC BY). http://creativecommons.org/licenses/by/4.0/

(c) (i) Open Access

\section{Abstract}

The two most common techniques available for diagnosis of malaria in Nigeria are microscopy and rapid diagnostic tests (RDTs). However, in diagnosing asymptomatic Plasmodium parasitaemia among donors, the preferred technique should not only be timely but must not compromise diagnosis. It should be more sensitive with minimal chances of false negative results. This study was carried out to compare microscopy and RDTs as effective tools for diagnosis of Plasmodium parasitaemia among blood donors in Port Harcourt. There were 200 donors involved in the study among which $135(67.5 \%)$ tested positive and $65(32.5 \%)$ tested negative on microscopy whereas $30(15.0 \%)$ tested positive and $170(85.0 \%)$ tested negative to RDT with a statistically significant difference between both techniques. Data were analysed using the statistical package epi-info version 7.02. We therefore recommend that microscopy using giemsa-stained blood films remain the method of choice for diagnosis of Plasmodium parasitaemia among blood donors to prevent the spread of transfusion malaria.

\section{Keywords}

Blood Donors, Microscopy, Rapid Diagnostic Tests

\section{Introduction}

Malaria is a common but highly fatal febrile illness caused by parasites of the genus Plasmodium. There are currently five species of the parasite that are known to cause infections in humans. Plasmodium falciparum

\footnotetext{
"Corresponding author.
}

How to cite this paper: Wariso, K.T. and Oboro, I.L. (2015) Diagnosis of Malaria among Blood Donors in Port Harcourt, Nigeria: Microscopy or Rapid Diagnostic Tests? Advances in Microbiology, 5, 358-363. 
which is the specie known to cause severe malaria that is associated with a high mortality rate is prevalent in Nigeria. It is much more severe in clinical presentation and can be fatal within a few hours of the first symptoms [1].

The World malaria report 2014 reports about 198 million cases and 584,000 deaths from malaria (mostly among African children) and 97 countries with ongoing malaria transmission [2]. In the Niger delta region of Nigeria, Erhabor and colleagues recorded a 10.2\% prevalence of Plasmodium parasitemia among blood donors [3] while other researchers across Nigeria and Africa have reported prevalence rates ranging from $13 \%$ to $77.4 \%$ [4]-[7].

Transfusion malaria which is malaria transmitted by transfusion of blood from infected donors is one of the most common transfusion-transmissible infections [8] [9]. Most donors implicated in transfusion-transmitted malaria live in malarious areas and so are predominantly semi-immune with very low parasite loads and the estimated infectious dose is 1 to 10 parasites per unit of blood [8].

Microscopic examination of stained blood smears remains the "gold standard" for detection of malaria parasitemia. The sensitivity of this method can be excellent, with detection of malaria parasite densities as low as 5 to 10 parasites/ $\mu$ l of blood [10]. Microscopy permits determination of the infecting species, the stage of the circulating parasites and monitoring of the parasitological response to anti-malarial therapy as well as the determination of circulating parasite density which may aid in prognosis [11]. In addition, examining an individual sample is relatively inexpensive and smears for malaria parasite detection provide a permanent record for quality assessment of the microscopic diagnosis.

Despite these strengths, microscopy possesses a number of limitationsviz: the procedure is labor-intensive and time-consuming and variability in stains used and techniques employed to collect and process blood affects slide interpretation [11] [12]. Mixed infections may also be missed, especially when $P$. malariae or $P$. ovale parasites are present, as their densities are often low in comparison to that of P. falciparum. Diagnostic errors in microscopy however, more commonly occur for low-density parasitemias (10 to 100 parasites/ $\mu$ l of blood), but errors of quantification can also occur with higher densities of $>5000 / \mu l$ and especially $>20,000 / \mu l$ of blood [13]. Accurate microscopic diagnosis is however, a skill that is mastered with extended training and experience [13].

Newer technological methods have emerged as alternatives to microscopy and they include antigen detection techniques, serology for antibodies, fluorescence microscopy (Quantitative buffy coat), flow cytometry, molecular amplification assays, and laser desorption mass spectrometry [11].

Malaria Rapid Diagnostic Tests (RDTs) employ lateral-flow immunochromatographic technique [14] [15].

The characteristics of the malaria antigen target and the detection antibodies are vital to understanding the performance of RDTs. Malaria antigens currently used as diagnostic targets are either specific to a Plasmodium specie or cut across the human Plasmodium species. P. falciparum-specific monoclonal antibodies have been developed for histidine-rich protein 2 (HRP-2) [16] [17] while Targets conserved across all human Plasmodium species (pan-Plasmodium antigens) have been identified on Plasmodium lactate dehydrogenase (PLDH) and aldolase enzymes [18] [19].

RDTs being simple to perform can be used by unskilled persons without formal medical laboratory training or even by travellers for self-diagnosis and treatment [11] [20]. This is a major advantage of RDTs in resource poor settings like ours.

Limitations of RDTs include the ability of these tests to give false positive and false negative results due to the persistence of the target antigens, their inability to detect mixed infections, inability to distinguish every specie of Plasmodium, failure to detect infections with low but clinically relevant concentrations of parasites (such as in asymptomatic infections in donors) and limited ability to monitor responses to therapy [21] [22].

This study was carried out to compare Giemsa-stained blood film microscopy and malaria rapid diagnostic test as methods for detection of Plasmodium parasitaemia among blood donors in Port Harcourt.

\section{Materials and Methods}

This study was carried out in the University of Port Harcourt Teaching Hospital located in Port Harcourt in the South-south geopolitical zone and Niger delta region of Nigeria. The University of Port Harcourt Teaching Hospital is one of the only two tertiary health institutions in Rivers state that serves a large proportion of people living in Southern Nigeria.

Ethical approval was obtained from the ethical committee of the hospital before commencement.

Two hundred blood donors were studied. From each of these, $2 \mathrm{ml}$ of venous blood was collected using an 
Ethylene Diamine Tetra-acetic Acid (EDTA)-containing vacutainer tube and needle. Thick and thin blood smears were made from each sample, allowed to air-dry and fixed in methanol. All smears were then stained with $10 \%$ Giemsa solution using standard procedure and examined microscopically under oil immersion. Asexual stages of Plasmodium parasites were identified where present and reported as positive.

Each sample was also subjected to malaria RDT using the SD BIOLINE Malaria Ag P.f Test kit (Standard Diagnostics) according to manufacturer's instructions. Microscopy and RDT were performed by different technicians and each was blinded from the other.

Data obtained was analyzed using the statistical package Epi-info version 7.02. The level of significance was set at 0.05 .

\section{Results}

The mean donor age was $32.13 \pm 6.25$ (mean \pm SD) with a range of twenty-one (21) to forty-five (45) years.

The majority of donors accounting for $97.5 \%$ (195) were male while females accounted for just $2.5 \%$ (5) of all donors screened with the difference being significant statistically $\left(\chi^{2}=361.00, p\right.$-value $\left.=0.001\right)$ (Table 1$)$.

Fifty-five percent (55\%) of donors were aged between twenty-six and thirty-five years, twenty-five percent (25\%) between thirty-six and forty-five years while only twenty percent (20\%) were $\leq 25$ years of age (Table 1).

The prevalence of Plasmodium parasitaemia using Giemsa-stained blood films and that using RDTs were compared and differed widely. One hundred and thirty-five donors (67.5\%) tested positive and sixty-five (32.5\%) tested negative to microscopy (Table 2) whereas thirty (15.0\%) tested positive and one hundred and seventy (85.0\%) tested negative to RDT (Table 3). This shows that over 50\% of infected persons in this study were missed by the RDT and that is a very large proportion.

Table 4 shows the comparative analysis between both diagnostic techniques and reveals that the difference was statistically significant $\left(\chi^{2}=111.58, p=0.001\right)$.

\section{Discussion}

The emergency donation of blood still occurs quite commonlyin a large proportion of Nigerian health institu-

Table 1. Age and sex distribution of donors.

\begin{tabular}{|c|c|c|c|}
\hline Characteristics & Frequency (\%) & Chi-square $\left(\chi^{2}\right)$ & p-value \\
\hline \multicolumn{4}{|c|}{ a) Sex Distribution of Donors } \\
\hline Male & $195(97.5)$ & \multirow[t]{2}{*}{131.64} & \multirow[t]{3}{*}{0.001} \\
\hline Female & $5(2.5)$ & & \\
\hline \multirow[t]{2}{*}{ Total } & $200(100.0)$ & \multirow{6}{*}{64.50} & \\
\hline & b) Age Distribution & & \multirow{5}{*}{0.001} \\
\hline$\leq 25$ & $40(20.0)$ & & \\
\hline $26-35$ & $110(55.0)$ & & \\
\hline $36-45$ & $50(25.0)$ & & \\
\hline Total & $200(100.0)$ & & \\
\hline
\end{tabular}

Table 2. Prevalence of plasmodium parasitaemia among blood donors using microscopy.

\begin{tabular}{ccc}
\hline MP (Using Giemsa stain) & Frequency & Percent \\
\hline Positive & 135 & $67.50 \%$ \\
Negative & 65 & $32.50 \%$ \\
Total & 200 & $100.00 \%$ \\
\hline
\end{tabular}

MP = Malaria parasite 
Table 3. Prevalence of plasmodium parasitaemia among blood donors using RDT.

\begin{tabular}{ccc}
\hline MP (using RDT) & Frequency & Percent \\
\hline Positive & 30 & $15.00 \%$ \\
Negative & 170 & $85.00 \%$ \\
Total & 200 & $100.00 \%$ \\
\hline
\end{tabular}

MP = Malaria parasite

Table 4. Comparison between Malaria RDT and Microscopy.

\begin{tabular}{ccccc}
\hline $\begin{array}{c}\text { Diagnosis of Plasmodium Parasitaemia } \\
\text { among Blood Donors }\end{array}$ & $\begin{array}{c}\text { RDT } \\
\mathbf{N}=\mathbf{2 0 0}(\%)\end{array}$ & $\begin{array}{c}\text { Giemsa Stain } \\
\mathbf{N}=\mathbf{2 0 0}(\%)\end{array}$ & CHI-Square $\left(\chi^{2}\right)$ & $\boldsymbol{p}$-Value \\
\hline Positive & $30(15.00)$ & $135(67.50)$ & & 111.58 \\
Negative & $170(85.00)$ & $65(32.50)$ & $0.001^{*}$ \\
\hline
\end{tabular}

*Significant $(p<0.05)$.

tions because the culture of routine blood donation is still quite poor among Nigerians. The method employed for pre-donation testing for malaria parasite in these situations is indeed critical because time would be of the essence; however, the balance between reduced testing time (reduced turnaround time) and accuracy must be maintained without impairing the quality of the diagnostic process.

Although Rapid diagnostic tests would seem the most feasible technique for diagnosis of malaria under such emergency settings due to the short testing time/reduced turnaround time associated with them, our findings reveal that microscopy using the giemsa-stained blood film leads to a much higher detection rate and therefore far more useful for diagnosis of asymptomatic Plasmodium parasitaemia among blood donors as this will greatly reduce the chances of missed diagnoses which may then result in transfusion malaria.

This finding is supportive of the fact that microscopy remains the gold standard for diagnosis of malaria as it is indeed more sensitive than RDTs. Some researchers have however, considered this a function of over-diagnosis of malaria using the giemsa-stained blood films due to human errors [23]. It is important to note that the rate of false positive results is greatly reduced when the microscopist is adequately trained and experienced [24]. This difference is probably due to geographical differences which account for the low prevalence of Plasmodium parasitaemia in that area.

The Centers for Disease Control and prevention (CDC) of the United States of America recommends that the need for malaria microscopy should not be eliminated by the use of RDT as the latter may not be able to detect some infections with lower numbers of malaria parasites circulating in the patient's bloodstream such as is most likely in asymptomatic parasitaemia seen in some donors and also because there is insufficient data available to determine the ability of the RDT to detect the 2 less common species of malaria, $P$. ovale and $P$. malariae [24].

Therefore all negative RDTs must be followed by microscopy to confirm the result. In addition, all positive RDTs also should be followed by microscopy because microscopy is needed to determine the species of Plasmodium that was detected by the RDT and for prognostication [24].

In addition, the cost effectiveness of the use of RDTs in Nigeria must be considered. The World Health Organization has stated that the cost-effectiveness of RDTs in areas of high prevalence such as Sub-Saharan Africa, in particular, has been controversial they are adjudged to be cost-effective in areas with prevalence of less than $20 \%$ which doesn't apply to Nigeria [25].

\section{Conclusion and Recommendations}

Though convenient and easy to use, RDTs still possess limitations that make their use for prevention of transfusion malaria limited in efficacy therefore since we cannot afford to continue to fuel transmission of malaria via blood transfusions, we recommend that microscopic examination of giemsa-stained blood films remain the method of choice for diagnosis of sub-clinical Plasmodium parasitaemia among blood donors. Encouraging the practice of Routine blood donations would afford the blood bank the time required for malaria microscopic diagnosis. 


\section{References}

[1] World Health Organisation (2014) Malaria, Country Profiles. http://www.who.int/malaria/publications/country-profiles/en/\#N

[2] World Health Organization (2014) World Malaria Report. http://www.who.int/malaria/publications/world_malaria_report_2014/report/en/

[3] Erhabor, O., Ok, O., Awah, I., Uko, K.E. and Charles, A.T. (2007) The Prevalence of Plasmodia Parasitaemia among Donors in the Niger Delta of Nigeria. Tropical Doctor, 37, 32-34. http://dx.doi.org/10.1258/004947507779951998

[4] Agboola, T.F., Ajayi, M.B., Adeleke, M.A. and Gyang, P.V. (2010) Prevalence of Malaria Parasite among Blood Donors in Lagos University Teaching Hospital, Lagos Nigeria. Annals of Biological Research, 1, 72-75. http://scholarsresearchlibrary.com/archive.html

[5] Badger-Emeka, L., Emeka, P. and Egbu, V. (2013) Prevalence of Malaria Plasmodium Parasite among Blood Donors at Nsukka Area, Southeast Nigeria. BEST: International Journal of Humanities, Arts, Medicine and Sciences, 1, 45-50.

[6] Mbanugo, J.I. and Emenalo, S. (2004) Prevalence of Malaria Parasitaemia among Blood Donors in Owerri, Imo State, Nigeria. Nigerian Journal of Parasitology, 25, 75-80.

[7] Muntaka, S. and Opoku-Okrah, C. (2013) The Prevalence of Malaria Parasitaemia and Predisposition of ABO Blood Groups to Plasmodium falciparum Malaria among Blood Donors at a Ghanaian Hospital. Assumption University Journal of Technology, 16, 255-260.

[8] Chauhan, V., Negi, R.C., Verma, B. and Thakur, S. (2009) Transfusion Transmitted Malaria in a Non-Endemic Area. JAPI, 57, 653-654. http://www.japi.org/september_2009/article_09.pdf

[9] Slinger, R., Giulivi, A., Bodie-Collins, M., Hindieh, F., St. John, R., Sher, G., Goldman, M., Ricketts, M. and Kain, K.C. (2001) Transfusion-Transmitted Malaria in Canada. CMAJ, 164, 377-379. http://www.cmaj.ca/cgi/reprint/164/3/377.pdf

[10] Moody, A. (2002) Rapid Diagnostic Tests for Malaria Parasites. Clinical Microbiology Reviews, 15, 66-78. http://dx.doi.org/10.1128/CMR.15.1.66-78.2002

[11] Murray, C.K., Gasser Jr., R.A., Magill, A.J. and Miller, R.S. (2008) Update on Rapid Diagnostic Testing for Malaria. Clinical Microbiology Reviews, 21, 97-110. http://dx.doi.org/10.1128/CMR.00035-07

[12] Warhurst, D.C. and Williams, J.E. (1996) ACP Broadsheet No. 148. Laboratory Diagnosis of Malaria. Journal of Clinical Pathology, 49, 533-538. http://dx.doi.org/10.1136/jcp.49.7.533

[13] Kilian, A.H., Metzger, W.G., Mutschelknauss, E.J., Kabagambe, G., Langi, P., Korte, R. and von Sonnenburg, F. (2000) Reliability of Malaria Microscopy in Epidemiological Studies: Results of Quality Control. Tropical Medicine International Health, 5, 3-8.

[14] Bell, D. and Peeling, R.W. (2006) Evaluation of Rapid Diagnostic Tests: Malaria. Nature Reviews Microbiology, 4, S34-S38.

[15] Lee, N., Baker, J., Andrews, K.T., Gatton, M.L., Bell, D., Cheng, Q. and McCarthy, J. (2006) Effect of Sequence Variation in Plasmodium falciparum Histidine-Rich Protein 2 on Binding of Specific Monoclonal Antibodies: Implications for Rapid Diagnostic Tests for Malaria. Journal of Clinical Microbiology, 44, 2773-2778. http://dx.doi.org/10.1128/JCM.02557-05

[16] Forney, J.R., Wongsrichanalai, C., Magill, A.J., Craig, L.G., Sirichaisinthop, J., Bautista, C.T., Miller, R.S., Ockenhouse, C.F., Kester, K.E., Aronson, N.E., Andersen, E.M., Quino-Ascurra, H.A., Vidal, C., Moran, K.A., Murray, C.K., DeWitt, C.C., Gray Heppner, D., Kain, K.C., Ballou, W.R. and Gasser Jr., R.A. (2003) Devices for Rapid Diagnosis of Malaria: Evaluation of Prototype Assays That Detect Plasmodium falciparum Histidine-Rich Protein 2 and a Plasmodium vivax-Specific Antigen. Journal of Clinical Microbiology, 41, 2358-2366. http://dx.doi.org/10.1128/JCM.41.6.2358-2366.2003

[17] Howard, R.J., Uni, S., Aikawa, M., Aley, S.B., Leech, J.H., Lew, A.M., Wellems, T.E., Rener, J. and Taylor, D.W. (1986) Secretion of a Malarial Histidine-Rich Protein (Pf HRP II) from Plasmodium falciparum-Infected Erythrocytes. Journal of Cell Biology, 103, 1269-1277. http://dx.doi.org/10.1083/jcb.103.4.1269

[18] Hayward, R.E., Sullivan, D.J. and Day, K.P. (2000) Plasmodium falciparum: Histidine-Rich Protein II Is Expressed during Gametocyte Development. Experimental Parasitology, 96, 139-146. http://dx.doi.org/10.1006/expr.2000.4557

[19] Makler, M.T., Piper, R.C. and Milhous, W.K. (1998) Lactate Dehydrogenase and the Diagnosis of Malaria. Parasitology Today, 14, 376-377. http://dx.doi.org/10.1016/S0169-4758(98)01284-8

[20] Genrich, G.L., Guarner, J., Paddock, C.D., Shieh, W.J., Greer, P.W., Barnwell, J.W. and Zaki, S.R. (2007) Fatal Malaria Infection in Travelers: Novel Immunohistochemical Assays for the Detection of Plasmodium falciparum in Tissues and Implications for Pathogenesis. American Journal of Tropical Medicine and Hygiene, 76, 251-259.

[21] Lesko, C.R., Arguin, P.M. and Newman, R.D. (2007) Congenital Malaria in the United States. A Review of Cases 
from 1966 to 2005. Archives of Pediatrics and Adolescent Medicine, 161, 1062-1067. http://dx.doi.org/10.1001/archpedi.161.11.1062

[22] Sotimehin, S.A., Runsewe-Abiodun, T.I. and Oladapo, O.T. (2008) Possible Risk Factors for Congenital Malaria at a Tertiary Care Hospital in Sagamu, Ogun State, South-West Nigeria. Journal of Tropical Pediatrics, 54, 313-320. http://dx.doi.org/10.1093/tropej/fmn016

[23] Harchut, K., Standley, C., Dobson, A., Klaassen, B., Rambaud-Althaus, C., Althaus, F. and Nowak, K. (2013) OverDiagnosis of Malaria by Microscopy in the Kilombero Valley, Southern Tanzania: An Evaluation of the Utility and Cost-Effectiveness of Rapid Diagnostic Tests. Malaria Journal, 12, 159. http://dx.doi.org/10.1186/1475-2875-12-159

[24] Centers for Disease Control and Prevention (2015) Malaria Diagnosis. http://www.cdc.gov/malaria/diagnosis_treatment/diagnosis.html

[25] World Health Organization (2015) Determining Cost Effectiveness of Malaria Rapid Diagnostic Tests in Rural Areas with High Prevalence. http://www2.wpro.who.int/sites/rdt 